\title{
LA TRADICIÓN DEL EXEMPLUM EN EL DISCURSO HISTORIOGRÁFICO Y POLÍTICO DE LA ESPAÑA IMPERIAL*
}

\author{
VICTORIA PINEDA \\ Universidad de Extremadura
}

Entre las estrategias de que se sirven los historiadores y los consejeros del gobernante para hacer eficaz su mensaje destaca el uso de ejemplos. El exemplum no sólo sirve para actualizar el pasado - uno de los fines principales de la historia-, sino también para proponer modelos de conducta útiles y válidos -otro objetivo primordial-. Así considerado, el ejemplo es uno de los instrumentos más persuasivos y poderosos del lenguaje de la historia y de la política (ver Zorzetti 1980). Los estudios especializados en uno y otro campo, ejemplo retórico y discurso historiográfico, no han atendido de manera sistemática a la relación entre ambos, al menos en lo que toca al caso español.

Desde este punto de vista, y sólo a modo de introducción, me propongo, por una parte, examinar el concepto de ejemplo retórico, su tradición, sus diferentes usos y tipos y la clase específica de ejemplos convenientes a la escritura de la historia y de la teoría política. Y, por otra, analizar los criterios que rigen la aparición de ejemplos en los textos historiográficos y políticos escritos en España durante los reinados de Felipe II y Felipe III, con especial atención a aquellos autores que escribieron obras de los dos géneros. Cae fuera de este estudio la investigación de la presencia de los exempla en la historiografía medieval, así como el rastreo de los antecedentes medievales de los tratados renacentistas de que me ocupo (sólo como indicación de las múltiples implicaciones del asunto, ver el volumen de Brémond, Le Goff y Schmitt y los artículos recogidos por Berlioz y Polo de Beaulieu); asimismo renuncio al estudio del exemplum dentro del ámbito de la predicación, expuesto con erudición por Aragüés Aldaz 1999.

* Partes de este trabajo sirvieron de base para comunicaciones presentadas en el Meeting of the Society of Spanish and Portuguese Historical Studies (New York University, abril 2000) y en el Congreso internacional sobre El Brocense y las humanidades del siglo XVI (Universidades de Salamanca y Extremadura, Cáceres, noviembre 2000).

Rlit, LXVII, 133 (2005), 31-48 


\section{El eJEMPlo en la ANTIGÜEDAD y el RenACimiento}

La noción y funciones argumentativas del ejemplo se definen ya en la Retórica de Aristóteles, donde se presenta el paradeigma como una de las dos formas que existen para demostrar una proposición. Una es el entimema o silogismo retórico. La otra es el ejemplo, inducción que se lleva a cabo mediante la relación de «lo semejante con lo semejante» (1357b29): las analogías que se pueden establecer entre los hechos del presente y los del pasado permiten comprender el alcance de una situación determinada y prever sus posibles efectos. De manera indirecta el ejemplo actualiza el pasado y ofrece la posibilidad de inferir verdades generales de casos particulares, fenómenos ambos de especial relevancia en el discurso histórico.

Junto a Aristóteles, los tratados retóricos latinos delimitan la noción e importancia del exemplum. Là Rhetorica ad Herennium define: «El ejemplo es la cita de algún hecho o dicho del pasado con la mención expresa del nombre del autor» («Exemplum est alicuius facti aut dicti praeteriti cum certi nomine propositio», 4.49.62). Podrían aducirse otros testimonios complementarios, así como explicaciones de la conexión entre discurso oratorio y discurso histórico (por ejemplo, en Cicerón Orator, 34.120, De oratore 2.12.51, 2.14.62, y en Quintiliano 2.4.2, 10.1.31-34). Me limitaré a recordar un pasaje de la Institutio oratoria particularmente significativo:

Conviene que tengamos en cuenta no sólo los preceptos de la filosofía, sino que es más importante que conozcamos y consideremos continuamente aquellos hechos y dichos preclaros que nos legó la antigüedad. («Neque ea solum, quae talibus disciplinis continentur, sed magis etiam, quae sunt tradita antiquitus dicta ac facta praeclare, et nosse et animo semper agitare conveniet», 12.2.29).

Y poco después: «Cuanto valen los preceptos de los griegos así valen los ejemplos de los romanos, que es algo todavía mejor» («Quantum enim Graeci praeceptis valent, tantum Romani, quod est maius, exemplis», 12.2.31, ver Araguiés 1993b y 1999).

La preponderancia concedida al ejemplo sobre el precepto resultará clave en el discurso histórico y político del Renacimiento, que hace de los exempla su principal instrumento persuasivo y, a la vez, asegura con ellos la pervivencia de los valores morales de la Antigüedad. La comparación precepto-ejemplo llegará a convertirse en un lugar común que recorre la tradición europea a través de autores antiguos, como Séneca («Longum iter est per praecepta, breve et efficax per exempla», apud Nadel, p. 298); medievales, como John of Salisbury («siquidem exemplis saepe magis proficitur quam praeceptis», apud Von Moos, p. 218); y renacentistas, como Pier Paolo Vergerio («in horum [filosofía moral e historia] altero praecepta, 
quid sequi quidve fugere conveniat, in altero exempla invenimus», apud Regoliosi, p. 5) o Coluccio Salutati («scientiam non contentis preceptis et regulis tradidisse, infinitis exemplis [...] confirmavit», apud Struever, p. 76; ver Nadel y Stierle). El tópico de la ventaja del ejemplo sobre el precepto es precisamente eso, un tópico; en la práctica los autores recurren sistemáticamente a ambos: el precepto como propositio, el ejemplo como confirmatio. Grabes (p. 39) encuentra en la tradición de los «espejos» medieval y renacentista dos funciones generales: una descriptiva -el espejo refleja las cosas como son-y otra prescriptiva -el espejo muestra las cosas como deberían ser-, articulada precisamente a base de normas y exempla.

He mencionado los «valores morales de la Antigüedad». La presencia del exemplum implica, naturalmente, la construcción de modelos dentro de un sistema basado en la autoridad moral de estas figuras ejemplares. $\mathrm{O}$, por decirlo con el Diccionario de Autoridades, el ejemplo es el «caso o hecho sucedido en otro tiempo, que se propone y refiere, o para que se imite y siga, siendo bueno y honesto, o para que se huya y evite, siendo malo». Pero no es este sentido de la «ejemplaridad» de los modelos de acción, con las asociaciones éticas que supone, el que quiero tratar. Lo que me interesa ahora es simplemente el uso del ejemplo como artificio del discurso. Valga la definición del Tesoro de Covarrubias: «hecho, texto o cláusula que se cita para comprobar, ilustrar o autorizar un aserto, doctrina u opinión». Comprobar, ilustrar o autorizar. Podría concederse que comprobar y autorizar funcionan aquí como sinónimos para hablar de la confirmación de una causa, pero desde luego ilustrar alude a una operación diferente. En el contexto retórico, illustrare se refiere a una forma de ornato que contribuye a la consecución de una de las virtudes oratorias, la perspicuitas.

El ejemplo, pues, opera en dos niveles: como confirmación del tema y como adorno estilístico. Esta última faceta es la que desarrolla Erasmo en su tratado De copia verborum ac rerum, donde se propone el ejemplo como uno de los modos de la amplificación retórica. La acumulación de ejemplos servirá para dotar de ornato al discurso otorgándole un estilo «copioso», ya que el exemplum sirve no sólo para que el caso parezca convincente, sino para iluminarlo, amplificarlo y enriquecerlo (De copia, p. 607). De hecho, se ha señalado que el método de elección de ejemplos («Ratio colligendi exempla») que propone Erasmo obedece más a criterios retóricos o estéticos que a criterios morales (Lyons, pp. 17-18). No hará falta subrayar que esta utilización puramente estilística del ejemplo rara vez — por no decir nunca- se produce a espaldas de la función argumentativa, sino que casi siempre actúa de forma complementaria. Se trataría de una cuestión de cantidad: uno o dos ejemplos confirman; es la acumulación lo que produce amplificatio y, de ahí, abundancia y adorno. A este respecto es notable el caso de la versión castellana (hacia 1340) de Fray Juan García de 
Castrojeriz del De regimine principum de Egidio Romano, en la que el traductor incluye glosas, citas bíblicas y patrísticas y gran cantidad de ejemplos sagrados y profanos.

En cuanto a las distintas especies de ejemplos, los tratados latinos habían hablado de exempla «históricos», es decir, reales, y exempla «poéticos», es decir, ficticios (Barthes dice que los reales incluirían no sólo los históricos, sino también los mitológicos, es decir, los provenientes de la tradición, que no han sido inventados por el autor, p. 200). Por otro lado, en algunas de las numerosas colecciones renacentistas de exempla, como la de Antonio Sabellico, se distingue entre ejemplos religiosos y ejemplos paganos. Una tercera diferencia es la que separa, dentro de los ejemplos reales, los antiguos de los recientes. El propio Erasmo habla de ejemplos ficticios, teológicos, bíblicos y filosóficos; antiguos, recientes y contemporáneos; e incluso los experimentados por el propio hablante (De copia, p.607). Dependiendo del género de que se trate, así se seleccionará la índole de los exempla: la poesía admite ejemplos ficticios; la historia, menos. En la historia el uso del exemplum es, si cabe, más importante que en cualquier otro género de discurso, pues el historiador «debe centrar su atención en los mejores logros de [los] antepasados, estimulando [...] con ello a emular sus más nobles y gloriosos hechos» (Skinner, p. 102). El requisito general es que se elija el ejemplo que tenga mayor fuerza, es decir, aquél que presente a un personaje cercano de alguna manera al receptor del discurso. En los espejos de príncipes, convendrá que los modelos sean soberanos o grandes jefes militares; cuando además se trate de la instrucción de un príncipe «cristiano», los ejemplos se extraerán también de las Escrituras.

Aparte de por su tratado De copia, Erasmo nos interesa por la obra que compuso unos años después, la Institutio principis christiani, publicada en 1516. Este texto, junto con Il principe de Maquiavelo, escrito en 1513 -aunque inédito hasta 1532-, y el Livre de l'institution du prince de Guillaume Budé, de 1517 -pero publicado treinta años más tarde-, conforma la base del género de tratados de regimine principis escritos en Europa a lo largo de los siglos XVI y XVII, que continuaba la tradición medieval del tratado de Egidio Romano (Hampton, p. 31; Truman, pp. 1231; Stegmann). El enfoque y el contenido de cada una de las obras es, por supuesto, de alcance muy diverso, pero ahora interesa observar sus rasgos comunes: fueron escritas casi simultáneamente y quizá por motivos parecidos, comparten el tipo de receptor y pertenecen al género deliberativo - el destinado a «mover a la acción»-. Pero tal vez uno de los más firmes lazos de conexión entre las tres sea su planteamiento del ejemplo: no sólo lo usan abundantemente como herramienta de persuasión, sino que incluso se detienen a explicar su importancia, y además proponen que el propio soberano a quien se dirigen se convierta en «figura ejemplar» para sus súbditos. 
En Il principe, al igual que en otras obras suyas (Bondanella, p. 9), Maquiavelo hace del ejemplo un instrumento tan fundamental y convincente que años después Francis Bacon aludiría a él asegurando que el mejor método para aprender filosofía moral «is that which Machiavel chose wisely and aptly for government; namely discourse upon histories or examples.» (Advancement of Learning, VI, apud Nadel, p. 311). En efecto, no hay página de El príncipe donde no aparezca un ejemplo, pocas veces sagrado, y casi siempre doble: el antiguo y el reciente. Pero acaso sea más interesante uno de los excursos que Maquiavelo hace al propósito, en el capítulo sexto:

Non si maravigli alcuno se, nel parlare che io farò de' principati al tutto nuovi e di principe e di stato io addurrò grandissimi esempli; perché, camminando gli uomini quasi sempre per le vie battute da altri, e procedendo nelle azioni loro con le imitazioni, né si potendo le vie d'altri al tutto tenere, né alla virtù di quelli che tu imiti aggiugnere debbe uno uomo prudente entrare sempre per vie battute da uomini grandi, e quelli che sono stati eccellentissimi imitare (p. 25; ver Rigolot, p. 560, y Strauss, p. 11).

Erasmo, que escribe su tratado para el príncipe «cristiano», encamina la selección de ejemplos hacia modelos religiosos, aunque no exclusivamente, y tiene cuidado de advertir que figuras como las de Aquiles, Jerjes o Julio César podrían producir un efecto negativo en una mente joven de carácter violento (p. 61). Aunque la aparición de exempla es más escasa en la Institutio que en El príncipe, no falta en ella una reflexión general y una llamada a la prudencia:

Los ejemplos de hombres ilustres inspiran vívidamente la imaginación del joven noble, pero las ideas de las que se alimenta son de la mayor importancia, pues ellas son la fuente del carácter que el joven desarrollará en su vida. Por lo tanto [...], debemos cerciorarnos de que desde el principio beba de las fuentes más puras y saludables [...]» (p. 10).

Por su parte, Budé, que, como Maquiavelo, usa en gran cantidad exempla paganos, también recomienda expresamente que el príncipe lea historia de la Antigüedad y de ella recoja ejemplos, y concluye su libro con la aclaración de que lo ha compuesto recolectando materiales diversos de autores griegos y latinos y «acumulando» las palabras y las hazañas de muchos grandes hombres, cuya autoridad había sido sancionada ya por los clásicos (apud Hampton, p. 34). Bastará una ojeada a los títulos de algunos capítulos para entender cómo él los lleva a la práctica: «El autor muestra en este pasaje por medio de dos buenos ejemplos, que trae del Rey Filipo, padre de Alejandro, cómo todos los reyes y príncipes deben observar la justicia» (capítulo 19, p. 119); «El autor trata cuán necesario le es al príncipe mantener su majestad y usarla siempre, alegando varios ejemplos de los romanos, que por ello adquirieron grande estima y reputación, con honor inmortal» (capítulo 38, p. 155). El lenguaje de estos enunciados evoca la 
filiación retórica del exemplum - el autor muestra, el autor alega- y resume la necesidad de los tratadistas de acudir a él para confirmar y a veces para amplificar. La asociación semántica entre ejemplo y demostración es notable en la mayoría de las obras y revela una conciencia general que va más allá de la orientación ideológica de los autores.

\section{TRATAdistas ESPAÑOLES}

Los tratados españoles, tanto historiográficos como políticos, se ajustan, por lo general, a lo dicho hasta aquí. El examen que sigue se centra en algunas de las obras más sobresalientes de ambos géneros, que se podrían agrupar en tres momentos cronológicos: los comienzos del reinado de Felipe II en la década de los cincuenta; el final de dicho reinado en la de los noventa; y el principio del siglo XVII, con el reinado de Felipe III.

En primer lugar, sobresalen por su importancia los tratados historiográficos o retóricos, así como los specula principis, escritos a mediados de siglo por autores españoles que desarrollaron su actividad en los Países Bajos. Los más importantes son Sebastián Fox Morcillo (De historiae institutione, 1557, De regni regisque institutione, 1561; ver también Cortijo Ocaña, 2000) y Fadrique Furió Ceriol (Institutionum rhetoricarum, 1554, El concejo y consejero del príncipe, 1551). Nos interesarán también otros dos humanistas españoles vinculados a los Países Bajos, que se caracterizan por la orientación religiosa de sus tratados: Felipe de la Torre, que publicó la Institución de un rey cristiano en 1555; y Arias Montano, por sus páginas de consejos a «reyes, príncipes y magistrados» en la Lección cristiana, obra algo más tardía que las anteriores (la versión latina se publicó en 1575; cito por la traducción de Pedro de Valencia, pp. 217ss.).

En los últimos años del siglo, coincidiendo con el final del reinado de Felipe II, se halla otro grupo de autores, en su mayoría jesuitas: Pedro de Ribadeneyra, autor de la obra antimaquiavelista Tratado de la religión y virtudes que debe tener el príncipe cristiano, para gobernar y conservar sus estados, contra lo que Nicolás Maquiavelo y los políticos deste tiempo enseñaron (1595); Juan de Torres, cuya Filosofía moral de príncipes para su buena crianza y para personas de todos los estados (1596) conocería al menos tres ediciones; y Juan de Mariana, autor de la monumental obra Historiae de rebus Hispaniae (1592) y del tratado De rege regisque institutione (1599). A estos tres jesuitas hay que añadir el nombre de Juan Costa, profesor de retórica y cronista oficial de la corona de Aragón, que publicó tanto un manual de Gobierno del ciudadano (1584; en realidad, se trata de la tercera edición aumentada y corregida de su obra El regidor $o$ ciudadano, de 1575), como un tratado historiográfico, el De conscribenda rerum historia (1591). 
Finalmente, ya durante el reinado de Felipe III, destacan los siguientes autores: Cabrera de Córdoba, con sus obras De historia, para entenderla y escribirla (1611) y Felipe Segundo, Rey de España (1619); el agustino Juan Márquez, que habría de convertirse en autor de éxito, a juzgar por las diez ediciones impresas en cinco décadas y las traducciones al italiano y al francés de su tratado El gobernador cristiano deducido de las vidas de Moisés y Josué, príncipes del pueblo de Dios (1612); el franciscano Juan de Santa María, autor de un Tratado de república y policía cristiana para reyes y príncipes, y para los que en el gobierno tienen sus veces (1618); y, en la década de los veinte, Eugenio Narbona y su Doctrina política civil, escrita por aforismos sacados de la doctrina de los sabios y ejemplos de la experiencia (1621), y Juan Pablo Mártir Rizo, autor de un Norte de príncipes (1626).

Aunque quede fuera del límite cronológico propuesto, no debemos dejar de citar, por la importancia de su pensamiento, a Juan Luis Vives. Vives no descuida el tópico de la oposición precepto-ejemplo, siempre en favor del ejemplo (De tradendis disciplinis, 1531), pero además es significativo el lugar que le concede a la explicación del exemplum dentro de su tratado retórico De arte dicendi (1532): el capítulo dedicado a la historia. El tono de Vives se aparta aquí momentáneamente del consejo de pura práctica retórica para subrayar la conveniencia moral de la historia:

conviene que todos los escritos tengan una utilidad [...] y cuánto más la historia, de la cual puede sacarse tanto provecho, a saber: experiencia de las cosas, prudencia, formación de costumbres a partir de ejemplos ajenos, de manera que sigamos lo mejor que se ha de hacer [...] y evitemos lo perverso» (p. 237).

Desde esta perspectiva moralizante, Vives advierte contra el uso arbitrario de ejemplos en un pasaje que deja entrever una cierta condena de la amplificatio indiscriminada: «el historiador ha de narrar aquellas cosas que contribuyan a la utilidad de la vida en común y puedan hacer mejores a los lectores, de modo que la escritura de hazañas no se consuma en vanidades y frivolidades» (idem), aunque más adelante reconocerá que existe un tipo de narración de hazañas «para el deleite y para retener los ánimos» (p. 239). La clase de ejemplos que recomienda, tanto religiosos como profanos, son los próximos al oyente: «ha de escribirse mucho y a menudo sobre los filósofos de los pueblos y sobre nuestros santos; estos ejemplos pueden ser muy útiles [...] Escríbase también sobre la gran probidad que los nuestros obtuvieron por la gracia divina» (p. 237; ver Kohut, pp. 347-356). Lo cercano a nosotros nos llega más y, por lo tanto, nos persuade mejor.

Los asuntos examinados por Vives responden, como se ve, a tres categorías fundamentales: a) naturaleza y funciones del ejemplo; b) ocasiones y estrategias de uso; y c) tipos de ejemplos. A estas tres categorías teóri- 
cas podría agregarse una cuarta de carácter pragmático: cómo funciona efectivamente el exemplum en el discurso histórico o político. Tomemos el esquema propuesto por Vives y veamos a continuación cómo articulan los autores estas categorías:

\section{a) Naturaleza y funciones del ejemplo}

Como se ha visto, el exemplum cumple las funciones de servir como herramienta para la argumentación y de contribuir al ornato. Aunque en general los autores no establecen divisiones tajantes, sí es posible distinguir su orientación en uno u otro sentido. Los más inclinados a la consideración del ejemplo como adorno son Furió y Fox. Furió distingue cuatro pasos al hablar de la prueba: proposición, argumentación, exornación y conclusión; el ejemplo sería una de las formas de la exornación, junto con el símil, el testimonio de alguna autoridad y otros (Institutionum, p. 166). Fox Morcillo asegura que la narratio se verá reforzada con el adorno que supone el uso de exempla, ya que no hay nada «más hermoso y excelente que dejar para la posteridad los ejemplos del pasado, los monumentos de dichos y hechos» (De historiae, ff. 42v, 79v). Juan Costa, por su parte, también explica el exemplum como modo esencial de amplificación (De conscribenda, libro II, p. 65).

Arias Montano usará los términos «dilatar», «amplificar» y «adornar», aunque no considera imprescindible la utilización de ejemplos y «curiosidades» (p. 287; ver más abajo la cita completa). Tampoco Francisco de la Torre ve la necesidad de incluir ejemplos - y ni siquiera preceptos- en su obra, pues basta con la simple doctrina: «No quiero decir que no sean éstos [los preceptos filosóficos o ejemplos de gentiles] buenos, y que leer no se deban, sino que hay mayor razón para que las leyes que Jesucristo nuestro legislador pone se lean y guarden»(Institución, f. A iii); aunque más adelante deja claro que los ejemplos, cuando se usan, sirven para «aprobación y persuasión» y no tanto para adorno (f. A iv).

Para el jesuita Juan de Torres, en cambio, los ejemplos no sólo son imprescindibles para confirmar y adornar, sino que pueden servir de guía firme para el gobernante: «aprovechará a los que tienen gobierno de la república el saber de los buenos consejos de los antiguos, el oír las maravillosas hazañas de los pasados, el ver lo que dejaron escripto los historiadores a los venideros, para que conforme a ello enderece cada uno sus acciones y sus pensamientos», cita que recoge tanto las nociones de precepto y ejemplo — «consejos de los antiguos», «hazañas de los pasados»como el vínculo que la historia establece entre el pasado y el futuro y también la cualidad moralizante del género (Filosofía moral, f. § 6v).

Finalmente, hay autores que consideran el exemplum ante todo como 
una forma de argumentación. El tratado de Luis Cabrera de Córdoba recoge los tópicos humanistas acerca de la historia, algunos de raigambre aristotélica: el de la historia como vínculo entre el pasado y el futuro («el que mira la historia de los antiguos tiempos atentamente y lo que enseñan guarda, tiene luz para las cosas futuras», De historia, f. 1), el de la utilidad moral de la historia, o el del ejemplo como conexión entre lo general y lo particular («el historiador [...] mira a lo universal, pues todo su fin es enseñar universalmente a vivir bien con los ejemplos, con las oraciones acomodadas a las personas, tiempos y casos; enseña a decir y hacer [...]», f. 12, f. 72v). Los ejemplos son la «útil conmemoración de alguna cosa hecha, o como hecha, [y,] para persuadir, buen argumento con inducción imperfecta, confirmando la parte con la parte» (ff. 73v-74). (Se ha advertido en la abundancia de ejemplos propuestos por Cabrera un efecto contraproducente, pues la eficacia del exemplum reside en su oportunidad y adecuación, no en la acumulación de ellos; Malavialle, p. 224).

El agustino Juan Márquez va incluso un paso más allá, pues su tratado sobre El gobernador cristiano está estructurado a base de sólo dos figuras ejemplares, Moisés y Josué, como se advierte ya desde el título. Se trata de un acercamiento opuesto al de Arias Montano o Felipe de la Torre; si aquéllos pensaban que la doctrina desnuda de ejemplos era suficiente, el tratado de Márquez corrobora la hipótesis contraria: la narración de la simple «verdad de los acaecimientos» no es suficiente, tiene poca utilidad, y por eso hay que completarla con ejemplos. Según asegura, «cuando para la prueba [de la] verdad no tuviéramos otros argumentos, nos bastarán a persuadir los que sabemos por las historias [i.e., ejemplos]» (p. 1, cursivas mías). Es reveladora a este respecto la carta que el Duque de Feria le escribe a Márquez en 1604 para solicitarle la escritura del tratado; en ella leemos que «las materias tratadas de propósito no entran tanto ni se persuaden como probadas con los ejemplos, y éstos por ninguna vía tan bien como con la historia, la cual escrita solamente con la verdad de los acaecimientos, sin que se descubran los consejos y se haga juicio de los discursos y sucesos, tiene sequedad y poca utilidad» (f. § 6). Los ejemplos de Márquez, según ha estudiado Borrego-Pérez (2002), revelan una tradición apegada por completo a los exempla religiosos y contrapuesta a los nuevos usos de Bodin, que se dejaría guiar más por «la raison et lumière naturelle» (p. 126).

\section{b) Estrategias de uso}

El discurso histórico es especialmente propicio para el uso de ejemplos, según anunciaba ya Quintiliano. Pero no es sólo que la historia proporcione el marco adecuado para la inserción de exempla, sino que ella 
misma se ve enriquecida con su presencia. A este respecto, Fox asegura que si la historia es útil para todos, lo es en especial para el gobernante (De historiae, f. 100), y esto se debe, entre otros motivos, a que proporciona modelos de vida (f. 94v), que incitan a la consecución de la virtud (f. 96). En un plano más técnico, Fox clasifica los géneros históricos en crónicas, comentarios, anales, diarios, narraciones breves y vidas. El exemplum es la forma característica de la narración breve, y en opinión de Fox, debe ir siempre enderezado a la «recta institución de la vida humana» (f. $24 \mathrm{v}$ ), por lo que hay que evitar la presentación de ejemplos torpes, otro tópico predilecto de la historiografía renacentista, que ya vimos a propósito de Erasmo. Fox, como Vives, es partidario de medir la frecuencia de los ejemplos (f. 36), aunque, como él, admite que es mejor no presentar una narración desnuda, sino «adornada» con los atavíos y la «fuerza de los ejemplos» (f. 42v).

Igual que Fox Morcillo, Cabrera de Córdoba dedica una sección a la figura del historiador, su talante, su formación y sus costumbres. Y como la obra de su antecesor, también la de Cabrera aconseja específicamente que el historiador sea versado en ejemplos de la Antigüedad, además de erudito, elocuente, grave, entero, severo, urbano, etc. (De historia, f. 15v). La materia de la historia será «ilustre, grave [y] abundante en ejemplos» (f. 28), pero evitará las digresiones inútiles (ff.31-31v, 60v) y siempre desechará los exempla deshonestos, que más sirven "para estragar las vidas que para reformarlas» (f. 54); incluso los «casos de amores» deben ser contados con «honestidad» (f. 54v). El lugar más adecuado para los ejemplos en el discurso histórico es el de la confirmación, pues, según acabamos de recordar, Cabrera concibe el exemplum como instrumento argumentativo.

\section{c) Tipos de ejemplos}

No siempre los autores distinguen sistemáticamente los tipos de ejemplos, pero sus comentarios suelen evidenciar qué criterios regirían esa hipotética distinción. Así, para Fox Morcillo, en la escritura de la historia se debe huir de ejemplos que no sean los óptimos y también de los que no guarden similitud con el lector (De historiae, f. 78, 96-96v; ver Costas Rodríguez, pp. 550-551). Las narraciones de los poetas quedan absolutamente proscritas por fabulosas, mendaces y llenas de ejemplos viciosos (f. 101v; ff. 98-98v). Juan Costa volverá a plantear la cuestión de los ejemplos no aptos (De conscribenda, libro II, p. 7).

Una de las distinciones más frecuentes es la que enfrenta a los ejemplos religiosos con los ejemplos profanos, asunto que preocupa sobre todo a los autores de espejos de príncipes cristianos. Así, Felipe de la Torre 
aclara en su Institución de un rey cristiano: «verdad es que [en la obra] hay algunas cosas de gentiles y profanos autores, pero son pocas y servirán para mayor aprobación y persuasión de lo que es divino», donde no deja de advertirse la paradoja de que los ejemplos gentiles son los que ayudan a aprobar los divinos y no al revés (f. A iv; ver también Francisco Monzón y Alfonso de Orozco).

Se suelen diferenciar también los ejemplos antiguos de los contemporáneos: los antiguos otorgan la autoridad sancionada por los siglos; los contemporáneos ofrecen inmediatez y cercanía. Encontramos ejemplos «cercanos» junto a los clásicos - «multis exemplis tum antiquis tum recentibus»en la obra de Juan de Mariana (De rege, p. 65), que ya desde la introducción avisa del papel relevante que el artificio ocupa en las páginas del tratado: «in ea historia, multa et praeclara principum virorum exempla consideravi» (f. [A i $]$ ).

\section{d) La práctica}

Además de su propia práctica en el uso de ejemplos —en la que entraremos seguidamente-, a veces los autores nos han dejado consejos sobre qué ejemplos específicos elegir o dónde ir a buscarlos. Fox Morcillo, para empezar, asegura a este respecto que el historiador deberá preocuparse por adquirir una formación completa en cuanto al conocimiento de antigüedades, ejemplos, dichos, costumbres, etc. (De historiae, f. 84), y para ello deberá leer, entre otros autores, a Quintiliano, que le brindará gran copia de modelos (f. 94). Él mismo ofrece al lector una especie de guía de figuras ejemplares: para la justicia, Aristides, Sócrates, Catón; para la fortaleza, Epaminondas, Temístocles; etc., a la que añade una pequeña relación de ilustres viciosos: Cómodo, Calígula, Nerón, etc. (ff. 98-98v). La fuente de Fox es siempre el clasicismo pagano.

Llama la atención que en los tratados políticos de autores como Fox y Furió - que tanto se preocupan por teorizar sobre el exemplum - sea tan escasa la presencia de ejemplos. El motivo puede ser la suposición de que el destinatario no tiene tiempo de detenerse en minucias o posee suficientes conocimientos como para poder comprender los preceptos sin más. En este sentido, Furió escribe en el prólogo de la obra:

sólo a manera de memorial apunto mi parescer sin amplificación ni pruebas [las dos funciones del ejemplo], por no fatigar con multitud de palabras los delicados oídos de quien continuamente está ocupado»(El concejo, f. B iv)

Pero poco antes había afirmado:

la institución del príncipe no es otro sino una arte de buenos, ciertos y aprobados avisos, sacados de la experiencia luenga de grandes tiempos, forjados 
en el entendimiento de los más ilustres hombres desta vida, confirmados por la boca y obras de aquéllos que por su real gobierno y hazañas memorables merescieron el título y renombre de buen príncipe» (f. A vii, cursivas mías).

Los pocos ejemplos de las dos obras nombran a personajes clásicos y en ambas hay una mención bíblica a David; Fox además incluye a Alfonso, Rey de Nápoles.

Las ocasiones del uso de ejemplos en el tratado de Fox —algo más pródigo que el de Furió- se concentran a propósito de varios asuntos: la necesidad de una buena educación, la preparación para la guerra, las virtudes, los vicios, etc. Muy hábilmente, el autor inserta ejemplos contemporáneos $\mathrm{o}$, si son ejemplos clásicos, saca de ellos derivaciones útiles a algún aspecto de la vida social o política del momento. Esta continua actualización de las enseñanzas del pasạdo - a través de los exempla- es, tal vez, uno de los rasgos más notables del tratado.

La escasez de ejemplos es también característica en el texto de Arias Montano, en el que el autor declara expresamente: «No hemos puesto cuidado en dilatar y amplificar esta cristiana instrucción con abundancia de palabras, o adornarla con variedad de curiosidades, contentándonos con declarar la doctrina [...] con estilo no demasiadamente largo ni oscuro ni dificultoso» (p. 287). Los rarísimos ejemplos que aduce provienen todos de la Biblia, como corresponde a un manual de «lección cristiana».

La lectura de los tratados de la época pone de manifiesto que no existen criterios estrictos con respecto a la selección de los ejemplos. Así, la Institución de Felipe de la Torre, dirigida a «un rey cristiano», no tiene inconveniente en alegar las figuras de Alejandro Magno o Darío, al lado de Constantino, como modelos para el gobernante, si bien es verdad que la mayor parte de sus ejemplos proceden de las Escrituras y los Santos $\mathrm{Pa}$ dres, procedimiento coherente con el plan diseñado para la obra (ver más arriba).

Abundantísimos, en cambio, son los ejemplos en el tratado de Juan Costa acerca del Gobierno del ciudadano, en el que, por cierto, aparece una poco frecuente sección en la que «se traen muchos ejemplos de damas que fueron mucho en armas y letras, y se trata de sus loores», p. 318). Igualmente copiosa es la presencia de ejemplos en otra obra publicada por los mismos años, la Filosofía moral de Juan de Torres; el tratado va destinado principalmente para uso de predicadores y por eso no resulta extraña la gran cantidad de ejemplos acumulados, tanto religiosos como profanos (Torres sí indica que es el texto sagrado el que confirma la validez de los dichos y hechos de gentiles y no al revés). Cualquier predicador que hablase para el rey podía encontrar en estas páginas, además de una instrucción básica en filosofía moral, un rico depósito de temas para sus sermones. De hecho, algunos capítulos se sustentan únicamente con la narración de ejem- 
plos, y si despojáramos a la obra de ellos, los preceptos cabrían en apenas unas pocas páginas.

El mismo cometido amplificativo cumplen los exempla en el antimaquiavelista Tratado de la religión y virtudes que debe tener el príncipe cristiano del también jesuita Pedro de Ribadeneyra, obra que contiene ejemplos de reyes españoles - Fernando el Católico, Carlos V- antepasados cercanos del destinatario del texto, el entonces todavía Príncipe Felipe.

Cabrera de Córdoba es otro autor que ilustra su discurso con exempla y autoridades frecuentes. El procedimiento que sigue en su Felipe Segundo, Rey de España consiste en acompañar la narración de los hechos con ejemplos del pasado y con preceptos, generalmente en forma de sentencias, lo que permite que la obra combine los géneros histórico y político. Así, a la sentencia «sin el temor de Dios se arruina el imperio» se le suma el ejemplo de impiedad de Heliogábalo, lo cual da pie a la narración de las preocupaciones de Felipe II sobre las discordias religiosas en Francia (p. 255). Otras veces, narra primero los hechos (el Rey ya ha provisto un cargo vacante), a continuación inserta el ejemplo («cuando el Rey Agesilao vio a su Lisandro privado de igualdad...») e inmediatamente coloca el precepto y la sentencia («Cuando [los supremos] andan envueltos con la fortuna, olvidan la consideración, cortesía, humanidad [y] conocimiento», p. 700).

Encontraremos en otras ocasiones que los ejemplos pueden aparecer acompañados de símiles, otro de los modos de argumentación. Es el caso del Tratado de república de Fray Juan de Santa María, quien en la dedicatoria de la obra deja clara su intención de recurrir a estos artificios, y donde los exempla sagrados conviven con los profanos.

El tratado de Fray Juan Márquez es peculiar en el sentido de que, como se ha dicho, extrae su doctrina de sólo dos figuras ejemplares, las de Moisés y Josué, a partir de las cuales saca los preceptos necesarios al gobernante, que a su vez ilustra con otros ejemplos de la Antigüedad. Peculiar, aunque en otro sentido, es también la Doctrina política civil de Eugenio Narbona, en la que hallamos una teoría sin elaborar, por así decir, pues el texto no es otra cosa que una lista de citas de autores, religiosos y profanos, antiguos y recientes, que deja ver al desnudo el mecanismo de asociar exempla a un total de 294 preceptos numerados. El autor encuentra el aval del recurso al ejemplo en autoridades como Tácito y el Padre Mariana.

Juan Pablo Mártir Rizo, en fin, además de alegar en su Norte de príncipes (1626) ejemplos, a veces muy largos y entreverados de sentencias, y otras veces más cortos como confirmación breve a un precepto, presenta la particularidad de servirse de ellos no sólo como confirmatio, sino también como refutatio de los exempla de Maquiavelo, quien, dice, «erró en la elección» de ejemplos, pues «sus escritos no eran poemas, no habían de mover los afectos de horror y conmiseración, sino educar [...] a los reyes y príncipes, no con doctrinas de tiranos, sino con razones y ejemplos virtuosos» 
(f. 93). Y para «reprobar la doctrina» de Maquiavelo no acudirá a «sentencias de santos y filósofos [porque] hacerlo así no sería prueba, sino amontonar sentencias sin descubrir la verdad» (f. 93v-94), por eso él prefiere «la razón y el ejemplo» (f. 94). Además, Rizo publicó otras obras analizando y glosando figuras «ejemplares»: Historia de la vida de Lucio Anneo Séneca (1625), Historia de la vida de Mecenas (1626), Historia trágica de la vida del Duque de Biron (1629) y Vida de Rómulo (1633). La función del exemplum en estas últimas obras, sobre todo en las «vidas» de Séneca y Mecenas, ha sido objeto de análisis en Delage 2002.

El exemplum como artificio argumentativo y amplificativo de la literatura política e historiográfica de los siglos de oro españoles sigue la práctica al uso en las obras de estos géneros publicadas abundantemente por el continente europeo. Las ideologías o la intención podían diferir, pero los recursos, de estirpe aristotélica, ciceroniana o erasmiana, eran los mismos. Sin embargo, en el caso español, este asunto apenas empieza a recibir la atención crítica que se merece (ver sobre todo Peraita, Araguiés, Azaústre y De Broce, Borrego-Pérez, Malavialle y Delage), a pesar de que, como espero haber demostrado, su presencia es inexcusable en los autores que configuraron el pensamiento de la época y se enfrentaron a las complejidades de historiar la filosofía de un imperio.

\section{BIBLIOGRAFÍA CITADA}

\section{Fuentes clásicas y renacentistas}

ARIAS MonTANo, Benito, Lección cristiana o tratado de lo que los discípulos de Cristo comúnmente deben saber [...] traducido del latín al español por Pedro de Valencia, Madrid, 1739.

ARISTÓTELES, Retórica, introducción, traducción y notas de Quintín Racionero, Madrid, Gredos, 1990.

BUDÉ, Guillaume, De l'institution du prince [1547], edición facsimilar, Farnborough, Gregg Press Limited, 1966.

CABRERA DE CóRDOBA, Luis, De historia, para entenderla y escribirla, Madrid, 1611.

-, Felipe Segundo, Rey de España, Madrid, 1619.

[CICERO], Rhetorica ad Herennium, edición y traducción Harry Caplan, Loeb Classical Library, Cambridge y Londres, Harvard University Press, 1989.

CostA, Juan, De conscribenda rerum historia libri duo, Zaragoza, 1591.

-, Gobierno del ciudadano, Zaragoza, 1584.

ERASMUS, Copia: Foundations of the Abundant Style [De duplici copia verborum ac rerum], traducción de Betty I. Knott, en James K. McKonica et al., eds., Collected Works of Erasmus, Toronto, University of Toronto Press, 1978.

-, The Education of a Christian Prince [Institutio principis christianis], traducción de Neil M. Cheshire y Michael J. Heath, Cambridge, Cambridge University Press, 1997. FOX MORCILlo, Sebastián, De historiae institutione dialogus, Amberes, 1557.

-, De regni regisque institutione, Amberes, 1561.

FURIÓ CERIOL, Fadrique, El concejo y consejeros del príncipe, Amberes, 1551. 
-, Institutionum rhetoricarum libri tres, Lovaina, 1554.

MACHIAVELli, Niccolò, Il principe, intr. Giuliano Procacci, Roma, Editori Riuniti, 1984. MARIANA, Juan de, De rege et regis institutione, Toledo, 1599.

MÁRQUEZ, Juan, El gobernador cristiano deducido de las vidas de Moisés y Josué, príncipes del pueblo de Dios, Salamanca, 1612.

MÁRTIR RIzo, Juan Pablo, Norte de príncipes, Madrid, 1626.

MONZÓN, Francisco, Espejo del príncipe cristiano, Lisboa, 1544.

NARBONA, Eugenio, Doctrina política civil, escrita por aforismos sacados de la doctrina de los sabios y ejemplos de la experiencia, Madrid, 1621.

OROZCO, Alfonso de, Regalis institutio ortodoxis omnibus, praecipue regibus, et principibus perutilis, Alcalá, 1565.

QUINTILIAN, Institutio oratoria, edición y traducción de E. H. Butler, 4 vols., Loeb Classical Library, Cambridge y Londres, Harvard University Press, 1979.

Ribadeneyra, Pedro de, Tratado de la religión y virtudes que debe tener el príncipe cristiano, para gobernar y conservar sus estados, contra lo que Nicolás Maquiavelo $y$ los políticos deste tiempo enseñaron, Madrid, 1595.

SANTA MARÍA, Fray Juan de, Tratado de república y policía cristiana para reyes y príncipes, y para los que en el gobierno tienen sus veces, Barcelona, 1618.

TORRE, Felipe de la, Institución de un rey cristiano, Amberes, 1555.

TORRES, Juan de, Filosofía moral de príncipes para su buena crianza y para personas de todos los estados, Burgos, 1596.

VIVES, Juan Luis, De arte retórica [De ratione dicendi], estudio introductorio de Emilio Hidalgo Serna; edición, traducción y notas de Ana Isabel Camacho, Barcelona, Anthropos, 1998.

—, Las disciplinas [De disciplinis], vol. I, traducción y notas de Marco Antonio Coronel Ramos, Valencia, Ayuntamiento de Valencia, 1997.

2. Referencias secundarias

ARAGÜÉs AldAZ, José, El «Fructus sanctorum» de Alonso de Villegas: estudio y edición del texto, [tesis doctoral en microfichas], Zaragoza, Universidad de Zaragoza, 1993.

-, «Humanismo y literatura ejemplar (Del pretendido rechazo al exemplum en la obra de Vives, Erasmo y Melchor Cano)», Juan Luis Vives. Acta del simposio celebrado con motivo del V centenario del nacimiento (Valencia, 5 a 9 de octobre de 1992), Manuel Mourelle de Lema, ed., Madrid, Grugalma, Colección Aula Abierta IV, 1993, pp. 121-147.

—, «El modelo de Valerio Máximo y la configuración de los ejemplarios renacentistas», en Actas del I Simposio sobre Humanismo y pervivencia del mundo clásico (Alcañiz, del 8 al 11 de mayo de 1990), Cadiz, Universidad de Cadiz, 1994, vol. I, pp. 267-282.

-, Deus concionator. Mundo predicado y retórica del exemplum en los Siglos de Oro, Amsterdam, Rodopi, 1999.

AZAÚSTRE GALIANA, Antonio, «Técnicas de argumentación retórica en Su espada por Santiago, de Francisco de Quevedo», Criticón, 71, 1997, pp. 105-115.

—, «Citas y ejemplos en la argumentación de Virtud militante, de Francisco de Quevedo», Scripta Humanistica in memoriam Manuel Taboada Cid, Manuel Casado Velarde, ed., La Coruña, Universidad de La Coruña, 1996, pp. 289-298.

BARTHES, Roland, «L'Ancienne Rhétorique. Aide-mémoire», Communications, 16, 1970 , pp. $172-229$.

Berlioz, Jacques y Marie Anne POLO DE BeAulieu, Les exempla médiévaux: Nouvelles perspectives, París, Honoré Champion, 1998. 
Bondanella, Peter E., Machiavelli and the Art of Renaissance History, Detroit, Wayne State University Press, 1973.

BorREgo-PÉREZ, Manuel, «La réfutation des exempla de Bodin dans l'oeuvre de Juan Márquez», L'exemplum narratif dans le discours argumentatif (XVI-XXe siècles), Manuel Borrego-Pérez, ed., París, PUF, 2002, pp. 113-126.

BRÉMOND, Claude, Jacques LE GOFF y Jean-Claude SCHMITT, L'exemplum, Turnhout, Brepols, 1982.

CORTIJO OCAÑA, Antonio, Teoría de la historia y teoría política en Sebastián Fox Morcillo. De historiae instituione dialogus. Diálogo de la enseñanza de la historia, Alcalá, Universidad de Alcalá, 2000.

COSTAS RoDRíGUEZ, Jenaro, «El tópico de la verdad en la historiografía latina renacentista», La recepción de las artes clásicas en el siglo XVI, Eustaquio Sánchez Salor, Luis Merino Jerez y Santiago López Moreda, eds., Cáceres, Universidad de Extremadura, 1995, pp. 543-554.

DE BROCE, Kathleen Bollard, «The Rhetoric of Exemplarity in Two Spanish SixteenthCentury Specula Principis», Symposium, 53, 1999, 83-91.

DELAGE, Agnès, «El exemplo particular no es bastante. L'exemplum narratif dans les récits biographiques de Juan Pablo Mártir Rizo», L'exemplum narratif dans le discours argumentatif (XVI-XXe siècles), Manuel Borrego-Pérez, ed., París, PUF, 2002, pp. 243-256.

GRABES, Herbert, The Mutable Glass. Mirror-imagery in Titles and Texts of the Middle Ages and English Renaissance, traducción de Gordon Collier, Cambridge, Cambridge University Press, 1982.

HAMPTON, Timothy, Writing from History. The Rhetoric of Exemplarity in Renaissance Literature, Ithaca y Londres, Cornell University Press, 1990.

KoHUT, Karl, «Retórica, poesía e historiografía en Juan Luis Vives, Sebastián Fox Morcillo y Antonio Llull», Revista de literatura, 104, 1990, pp. 345-374.

LyONS, John D., Exemplum. The Rhetoric of Example in Early Modern France and Italy, Princeton, Princeton University Press, 1989.

Malavialle, Renaud, 2002. «Exemplarité et historicité dans De historia (1611) de Luis Cabrera de Córdoba», L'exemplum narratif dans le discours argumentatif (XVI-XXe siècles), Manuel Borrego-Pérez, ed., París, PUF, 2002, pp. 223-241.

NADEL, George H., «Philosophy of History Before Historicism», History and Theory, 3, 1964, pp. 291-315.

Peraita, Carmen, «En torno a la circunstancia histórica de la Política de Dios I de Quevedo: 'auiendo de tener lado'», Studia aurea. Actas del III Congreso de la AISO, Toulouse y Pamplona, Universidad de Navarra, 1996, vol. III, pp. 389-398.

-, Quevedo y el joven Felipe IV. El príncipe cristiano y el arte del consejo, Kassel, Reichenberger, 1997.

REGOLIOSI, Mariangela, «Riflessioni umanistiche sullo 'scrivere storia'», Rinascimento 31, 1991, pp. 3-37.

RIGOLOT, François, «The Renaissance Crisis of Exemplarity», Journal of the History of Ideas, 59-4, 1998, pp. 557-563.

SKINNER, Quentin, Maquiavelo, traducción de Manuel Benavides, Madrid, Alianza, 1984. STEGMANN, André, 1986. «Le modèle du prince», Le modèle à la Renaissance, Claude Balavoine, Jean Lafond y Pierre Laurens, eds., París, Vrin, pp. 117-138.

STIERLE, Karlheinz, «L'Histoire comme Exemple, l'Exemple comme Histoire», Poétique, 10, 1972, pp. 176-198.

STRAUSS, Leo, «Machiavelli and Classical Literature», Review of National Literature, 1, 1970, pp. 7-25.

STRUEVER, Nancy S., The Language of History in the Renaissance. Rhetoric and Historical Consciousness in Florentine Humanism, Princeton, Princeton University Press, 1970. 
TRUMAN, Ronald W., Spanish Treatises on Government, Society and Religion in the Time of Philip II. The 'de regimine principum' and Associated Traditions, Leiden, Boston y Colonia, Brill, 1999.

VoN Moos, Peter, «The Use of Exempla in the Policraticus of John of Salisbury», The World of John of Salisbury Michael Wilks, ed., Oxford, Basil Blackwell, 1984, pp. 207-261.

ZORZETTI, Nevio, «Dimostrare e convincere: l'exemplum nel ragionamento induttivo e nella comunicazione», Mélanges de l'École Française de Rome 92.1 (Rhétorique et Histoire. L'exemplum et le modèle de comportement dans le discours antique et médiéval), 1980, pp. 33-65. 


\title{
RESUMEN
}

\section{La tradición del exemplum en el discurso historiográfico y político de la España imperial, por Victoria Pineda}

Entre las estrategias de que se sirven los historiadores y los consejeros del gobernante para hacer eficaz su mensaje destaca el uso de ejemplos. El exemplum no sólo sirve para actualizar el pasado - uno de los fines principales de la historia-, sino también para proponer modelos de conducta útiles y válidos - otro objetivo primordial-. Desde este punto de vista, el ejemplo es uno de los instrumentos más persuasivos y poderosos del lenguaje de la historia y de la política. Este trabajo examina, por una parte, el concepto de ejemplo retórico, sus diferentes usos y tipos y la clase específica de ejemplos convenientes a la escritura de la historia y de la teoría política. Y en segundo lugar analiza qué criterios rigen la aparición de ejemplos en los textos historiográficos y políticos escritos en España durante los reinados de Felipe II y Felipe III, con especial atención a aquellos autores que escribieron obras de los dos géneros.

Palabras clave: exemplum, historiografía, discurso político, espejos de príncipes, argumentación.

\begin{abstract}
This paper examines the theories of the rhetorical exemplum as presented in sixteenthcentury historiographical works, especially in connection with the writing of texts on the education of the prince. I study how the example is presented both as a tool of argumentation - as stated by Aristotle-, and as an instrument of amplification -as explained by Erasmus-. I analyze how the modern example (as presented in European historiography, and practised in treatises de regimine principum) is linked to classical rhetorical theory. The final section of the paper shows how all these relations are present in the works of humanist authors from the imperial court of Philip II. These authors wrote both texts on historiography, and books on the prince's education: Sebastián Fox Morcillo, Fadrique Furió Ceriol, Benito Arias Montano, and Luis Cabrera de Córdoba. Emphasis is given to the importance of exemplum as a link between the understanding of the past and the preparation for the future, and also between the presentation of particular facts and the explanation of general principles.
\end{abstract}

Keywords: exemplum, historiography, political discourse, mirrors of princes, argumentation. 